\title{
Políticas y factores que contribuyen a la transferencia de tecnología en organizaciones del Perú
}

\author{
Roca T., Santiago*
}

\section{Resumen}

En diversos países en desarrollo, entre ellos el Perú, se cree que basta fomentar el comercio y la inversión para que automáticamente las empresas extranjeras y el libre mercado transfieran en forma espontánea la tecnología. Este trabajo muestra que ello no es así. La transferencia de tecnología es un asunto complejo que requiere de determinación estratégica, políticas públicas, instituciones intermedias y capacidades a nivel de la empresa y de los individuos involucrados. Este estudio revisa la literatura de la transferencia de tecnología, tanto desde el punto de vista de las empresas como del gobierno y se centra en analizar 11 estudios de casos de transferencia tecnológica e innovación en el Perú. Se detecta que se requieren enfrentar ocho categorías de problemas que existen en los procesos de absorción y transferencia tecnológica: 1) capacidades individuales; 2) capacidades empresariales; 3) fallas de información, cooperación y coordinación; 4) vinculaciones y conexiones externas; 5) infraestructura; 6) financiamiento; 7) instituciones; y la 8) existencia de fuerzas propagadoras y sistémicas. El gobierno debe articular y hacer coherente el sistema tecnológico nacional y buscar el cumplimiento de los acuerdos de transferencia tecnológica establecidos con los organismos internacionales multilaterales.

Palabras clave: Transferencia de tecnología, capacidades para absorber conocimientos, política industrial y tecnológica.

\section{Recibido: 12-09-13 Aceptado: 19-06-14}

Profesor Principal de Economía, Escuela de Administración de Negocios para Graduados, Universidad ESAN, Lima, Perú. Director del Centro de Propiedad Intelectual, Innovación, Competencia, Consumidor y Comercio. Ph.D en Economía, Universidad de Cornell, USA. El autor agradece el apoyo parcial de la Fundación Friederich Ebert para la realización del presente trabajo. E-mail: sroca@esan.edu.pe 


\title{
Policies and Factors that Contribute to Technology Transfer for Organizations in Peru
}

\begin{abstract}
In diverse developing countries, including Peru, it is thought that fomenting trade and commerce will automatically cause foreign corporations and free markets to spontaneously transfer technology. This paper shows this is not true. Technology transfer is a complex issue that requires strategic determination, public policies, intermediary institutions and capacities at the levels of the company and of the individuals involved. This study reviews the literature about technology transfer from the viewpoints of the companies and the government, and analyzes eleven case studies about technology transfer and innovation in Peru. Eight major categories of problems to be confronted in the processes of absorbing and transferring technology were detected: 1) individual capabilities; 2) entrepreneurial capabilities; 3 ) information, cooperation and coordination failures; 4) external connections; 5) infrastructure; 6) funding; 7) institutions; and 8) the existence of systemic and propagating forces. The government should articulate and make the national technological system coherent and seek to comply with the technology transfer agreements established with multilateral international organizations.
\end{abstract}

keyword: Technology transfer, capacities to absorb knowledge, industrial and technological policies.

\section{Introducción}

En el Perú cómo en varios países en desarrollo recién se está empezando a tomar conciencia acerca del rol de la ciencia, tecnología e innovación en el crecimiento de las empresas y el progreso de la economía. En este proceso sin embargo parecen tener prioridad el desarrollo de la ciencia y la creación de nuevas tecnologías, descuidándose los procesos de transferencia tecnológica, los cuáles de encaminarse adecuadamente pueden ser más efectivos en elevar los estándares de creación de valor de las empresas y organizaciones. Aunque absorber tecnologías existentes es probablemente más eficiente y menos costoso que crear nuevas tecnologías, su concreción es un proceso complejo que está influenciado por decisiones de políticas públicas y una serie de requerimientos a nivel de las empresas $u$ organizaciones. Si bien la literatura y la experiencia internacional han aportado luces al respecto, la mayoría de ellas son parciales, enfocándose hacia algún aspecto o asunto específico. De otro lado, los pocos estudios de casos describen la experiencia empresarial pero raramente sistematizan o destilan en forma integral los factores que afectan el éxito de los procesos de transferencia tecnológica. Estos vacíos fueron los que originaron la realización de este trabajo.

Además de revalorar la prioridad que los países en desarrollo deben asignar a los procesos de transferencia o absorción de tecnologías en relación a la creación de nuevas tecnologías y el desarrollo de la ciencia, el objetivo del presente trabajo es contribuir a la mejora de las políticas públicas e institucionales de 
transferencia tecnológica y a la identificación de los factores específicos que influyen en el éxito de las empresas en absorber tecnologías. Se busca revalorar la prioridad que los países en desarrollo deben asignar a los procesos de transferencia o absorción de tecnologías.

La metodología utilizada incluyó en primer lugar la revisión en la literatura de las definiciones, mecanismos, políticas públicas y factores que influyen en la creación y transferencia de tecnología a nivel de la empresa, las instituciones y el sistema económico en su conjunto. El trabajo de campo implicó la revisión de 11 estudios de casos elaborados en una investigación promovida por el Programa de Ciencia y Tecnología del Consorcio de Investigación Económica y Social del Perú, en base a los cuáles el autor clasificó ocho categorías analíticas, seleccionando los "sucesos" relacionados a cada categoría que tuvieron una incidencia significativa en el éxito o dificultad de la transferencia tecnológica.

Al final se destilaron los principales factores y políticas a seguir para lograr el éxito de los procesos de transferencia de tecnología. Se plantean definiciones, canales y mecanismos por los cuáles se transfiere la tecnología y se revisa brevemente la literatura acerca de los principales restricciones y políticas públicas que afectan la creación y transferencia de tecnologías a nivel de la empresa, las instituciones y el sistema económico en su conjunto, incluido las restricciones del orden económico internacional. Se realiza un resumen la situa- ción general de la transferencia de tecnología en el Perú y se identifican - en base a 11 estudios de casos específicos- ocho grandes problemas o determinantes de éxito de los procesos de absorción y transferencia de tecnología.

\section{Definiciones y mecanismos de transferencia tecnológica}

Para delimitar claramente la investigación, se define primero que se entiende por tecnología y por transferencia de tecnología, el porqué de su control, y cuáles son los canales y mecanismos que se utilizan normalmente para la transferencia de tecnología.

\subsection{Definiciones}

La tecnología ha sido reconocida desde tiempos inmemoriales como uno de los elementos claves para el crecimiento económico. La teoría económica básica explica que la tecnología es el conocimiento aplicado en la actividad de producir bienes y servicios: el coeficiente A de la función de producción neoclásica del modelo de Solow, $Y=A F(L, K)$, donde $Y$ es el bien producido, A la tecnología y $L$ y K son los factores de producción trabajo y capital. Específicamente, Reddy y Zhao (1990), se refieren no solo a la tecnología incorporada en el producto, sino también a la del proceso de hacer el producto y a la información del cómo se usa y aplica el producto mismo ${ }^{1}$. Pavitt (1985) sugiere 
que tecnología es conocimiento diferenciado acerca de una aplicación específi$\mathrm{ca}$, que tiene componentes tácitos, no codificados, que son acumulativos en las empresas. La tecnología está incorporada en las personas, los materiales, los procesos físicos y cognitivos, las facilidades, las máquinas y las herramientas. Maskus (2004) amplía la definición al incluir como tecnología a la información necesaria para producir; el resultado de combinar o procesar insumos que incluyen los procesos, las estructuras organizacionales, las técnicas de gestión, el financiamiento, los métodos de marketing y cualquiera de sus combinaciones. Desde una perspectiva sistémica Afriyie (1988) define que la tecnología comprende: un sub-sistema de conocimiento bási$\mathrm{co}$, un sistema de soporte técnico (software), y una tecnología incorporada en el capital físico (hardware).

Transferir tecnología implica la transmisión de ese "saber cómo" que le permite al recipiente manufacturar un producto o proveer un servicio específico (Baranson, 1970). Ello incluye además la capacidad de aprender, desarrollar y luego producir autónomamente, la tecnología subyacente al producto (Chesnais, 1986). El concepto de transferencia de tecnología no solo se refiere a la transmisión del conocimiento o de la información, sino a la capacidad de los receptores de aprender y absorber la tecnología (Maskus, 2004). La transferencia de tecnología implica la transmisión de información, del saber cómo, del conocimiento técnico incorporado en los productos y procesos y en la gestión y administración. La tecnología y los conocimientos son inseparables, aunque algunos autores dis- tinguen que la transferencia de conocimientos se enfoca en un constructo más amplio dirigido hacia el porqué del cambio, mientras que la transferencia de tecnología se limita a unas cuantas herramientas o técnicas para cambiar algo específico (Sazali et al., 2012a).

\subsection{El porqué del control y los canales o mecanismos de transferencia tecnológica}

Según la literatura, las multinacionales (MNC) son la principal fuente de transferencia de tecnología ya que ellas invierten más del $80 \%$ del total de investigación y desarrollo (I\&D) de las empresas que existe en el mundo. El tema de la propiedad, control y dominio de la tecnología es de importancia vital para estas multinacionales y sus países de origen, ya que el que detenta y logra que la producción de la tecnología sea inimitable o no pueda ser absorbida por otros, mantiene la ventaja competitiva y obtiene generalmente mejores resultados económicos. El tema de la transferencia tecnológica es entonces un tema estratégico de las empresas y de sumo interés de los gobiernos.

Los principales canales que usan las multinacionales para transferir tecnología son: i) la exportación directa de bienes con tecnología incorporada, ii) las subsidiarias, iii) el licenciamiento y, iv) los joint ventures (Sazali et al., 2012b).

En la exportación directa de bienes de consumo no hay mucha transferencia de tecnología productiva porque ella está incorporada en los bienes que se venden y a menos que los receptores tengan las capacidades de "abrir y replicar", no hay aprendizaje sino uso de la tecnolo- 
gía, sin conocimiento del cómo desarroIlarla. El uso de la tecnología se difunde, no la producción de la tecnología. En casos de bienes de capital, sucede algo parecido, la transferencia de tecnología ocurre sólo en el operar, mantener y reparar el equipo o maquinaria, lo cual está generalmente a cargo de la firma importadora, distribuidora o proveedora. Las MNC pierden algo de control cuando exportan los bienes de capital, pero no pierden el control de la producción de la tecnología. Puede darse sin embargo el caso de exportaciones de bienes estrictamente tecnológicos (referidos a la producción de tecnología misma) los cuáles pueden ser vendidos por las empresas generadoras o por distribuidores de bienes tecnológicos.

Muchas veces, las MNC prefieren utilizar internamente las tecnologías a través de sus subsidiarias en vez de venderlas exportándolas, ya que mantienen un mejor control de sus tecnologías; ello lo hacen para cubrir sus gastos en I\&D, prevenir obsolescencia rápida de sus productos o ganar participación de mercado (Harris y Ravenscraft, 1991). Esto ocurre también cuando los costos de transacción son altos, la tecnología no está estandarizada, es difícil de codificar, o su contenido es tácito (Siddharthan, 1992, Kogut y Zander, 1993).

La transferencia de tecnología a través de licencias otorga permiso o da derecho a terceros a hacer, diseñar, distribuir o vender productos, procesos o servicios o a usar determinada patente, marca, diseño industrial y copyright. Incluye también la provisión de asistencia técnica y de gestión. El licenciatario paga una comisión, una franquicia, un royalty, o parte de las utilidades. Se usa para distintos propósitos de acuerdo a las estrategias empresariales. Zander y Kogut (1995) sugieren que las licencias son más apropiadas cuando las tecnologías son menos complejas y se aprenden rápidamente por las empresas locales $y$ cuando las MNC no conocen extensivamente los mercados locales y se requiere algunas adaptaciones. Mansfield y Romeo (1980) argumentan que a través de las licencias las multinacionales transfieren a terceros las tecnologías que son más antiguas en relación a las que transfieren a sus propias subsidiarias.

El mecanismo de usar joint ventures para transferir tecnología permite compartir diferentes habilidades y conocimientos entre asociados, sea para reducir los riesgos de la inversión, compartir saber tecnológico o gerenciar y mejorar la eficiencia operativa (Inkpen, 2000; Contractor y Lorange 1988). Los joint ventures se movilizan por razones de estructura y distancia organizacional, apertura relacional, empatía, propiedad, capacidad de absorción, experiencia previa, intentos de aprendizaje, y el ciclo de vida de la tecnología, entre otros.

\section{Existen otros canales culturales} - institucionales muy útiles para la absorción o transferencia de tecnología: i) la imitación, ii) el movimiento de personas, iii) los datos de prueba y las patentes, y, iv) los medios de comunicación y de distribución de tecnologías (Sazali et al., 2012b).

La imitación ocurre cuando las empresas locales tienen la capacidad de aprender observando la tecnología externa. Esta es mayor cuando hay mayor interacción entre las MNC y las empresas 
locales, cuando hay mayor rotación de personal, o cuando empleados de las transnacionales emprenden nuevos negocios, así como cuando se promueven encadenamientos hacia atrás, adelante y los costados. La reingeniería reversa y la inspección de productos fomentan la imitación.

El movimiento de personas se logra a través de la repatriación de los científicos e ingenieros, profesores y administradores, visitas de expertos a fábricas o proveedores, o cortas estadía de los empleados en programas de intercambio con otras empresas. Es importante también la contratación de ex empleados de las MNC, ya que ellos conocen la información tecnológica y la pueden incorporar a los nuevos negocios y territorios.

La información de patentes publicada en las oficinas de propiedad intelectual y en las bases de datos de patentes son una fuente de transferencia de conocimiento si los receptores son capaces de absorber y entender lo publicado y si las oficinas de patentes son rigurosas en exigir el uso claro del lenguaje y la redacción - al nivel del experto promedio en el estado de la técnica - cuando se describen los registros de patentes. La información de las pruebas de ensayo sobre la eficacia e idoneidad de los productos para el ingreso al mercado, así como los vademécums profesionales, son una fuente inmejorable de absorción de conocimientos y tecnologías. De igual manera la información contenida en las normas y reglamentos técnicos así como en los sistemas de evaluación de la conformidad, constituyen una fuente de difusión y transferencia tecnológica notable.
Un canal de transferencia de tecnología que facilita mucho la información y los conocimientos son las revistas especializadas y los medios de comunicación en general (radio, televisión y ahora la internet, google.com. entre otros) que se dedican a difundir una amplia gama de conocimientos, aunque la gran parte de ellos ya está en el ámbito público. Esto eleva los conocimientos básicos y la curiosidad de la gente y empresas en la ciencia, tecnología e innovación.

\section{Políticas públicas y factores que influyen en la creación y transferencia de tecnología}

Tanto en la literatura de la empresa como en la del crecimiento económico, la constante innovación de los conocimientos y la tecnología han sido reconocidas como una de las fuentes de ventaja competitiva de las empresas y como el motor del crecimiento económico. Por esa razón, las empresas como los gobiernos están siempre preocupadas por reconocer los factores y las políticas que influyen en la creación, absorción y transferencia de conocimientos y tecnologías. En esto el tema de la propiedad y el control de la tecnología tienen un rol preponderante, el propietario de la tecnología no va a querer transferir la tecnología sin obtener algo a cambio. Solo si el propietario de la tecnología no tiene interés en explotarla directamente, toma relevancia el tema de la venta, licenciamiento, franquicia y otras formas de transferir tecnología. Pero aún si la transferencia fuera parte de un programa de apoyo tecnológico gratuito de un país a otro país, no hay garantía 
que los receptores aprendan y se logre transferir la tecnología.

Por eso, el orden económico en transferencia de tecnología enfrenta contradicciones inexpugnables en los distintos niveles: i) a nivel de la empresa, ii) en los sistemas institucionales de intermediación, iii) a nivel de la economía en su conjunto y iv) en el orden económico internacional. En cada nivel, los intereses de unos enfrentan los intereses de los otros, lo que obliga en primer lugar a que los procesos de transferencia de tecnología no sean pasivos, sino requieren el interés activo y la determinación estratégica de quienes quieren absorber los conocimientos y desean mejorar y nivelarse. La transmisión de tecnologías no es un proceso automático que los tenedores van a realizar en forma espontánea; al contrario, los interesados deben encontrar las maneras de lograr que los tenedores transfieran las tecnologías y luego ellos mismos utilizarlas y mejorarlas para su propio beneficio.

En este sentido, a nivel de la empresa, la literatura encuentra que las unidades empresariales necesitan desarrollar capacidades para absorber o explotar la tecnología que reciben, adquieren o contratan y para administrarla (Wallender 1979; Speser, 2006). Estas capacidades van desde: 1) una estructura organizacional mínima, 2) capacidad interna para diagnosticar problemas e identificar los tipos de tecnología que serán de mayor valor, 3) evaluar la funcionalidad, características, rasgos y aplicaciones de alternativas tecnológicas competitivas, 4 ) analizar los riesgos y costos para adquirirlas, 5) alinear el mercado, la tecnología y las capacidades, 6) absorberlas y adaptarlas, 7) mantenerlas y mejorarlas y, finalmente; 8) desarrollar capacidades propias para investigación y nuevos desarrollos.

De otro lado, la teoría de comportamiento organizacional señala que las organizaciones aprenden y que en el tema de la transferencia de tecnología se necesita aprender a absorber conocimientos, a conectarse entre grupos, a interactuar, a confrontar ideas, a observar. El aprendizaje organizacional es un proceso que tiene diversas fuentes (congénita, la experiencia, la observación y réplica, los injertos y la investigación) a través de las cuáles se comparte información que lleva a nuevos entendimientos e interpretaciones y finalmente a su uso y explotación. La memoria de la organización guarda estos aprendizajes en la eventualidad que puedan servir o utilizarse parcial o íntegramente para otros desarrollos (Huber, 1991).

La transferencia de tecnología necesita también de políticas públicas y de un cúmulo de información y de coordinación y articulaciones que muchas veces no surgen espontáneamente en el mercado sino requieren de la actuación de diversos agentes e instituciones intermediarias. Se hace referencia a las instituciones de ciencia, tecnología e innovación y del sistema educativo nacional (básico y superior, incluyendo universidades e institutos tecnológicos); a las instituciones cuya tarea es brindar información, promover ferias, coordinar el calce entre ofertantes y demandantes; a las asociaciones empresariales; $y$ a las redes de la sociedad civil impulsadas por líderes visionarios que ensayan articulaciones virtuosas y coadyuvan a la transmisión de conocimientos y difusión tecnológica. El rol que estas instituciones juegan en la 
transferencia y difusión de conocimientos es a veces mayor al que puede existir a través del fomento de las relaciones intra y entre empresas (que tienen un papel mayor en la generación y producción de la tecnología). Especial cuidado hay que tener al desarrollar sistemas e instituciones de propiedad intelectual y de aseguramiento de la calidad, ya que estas deben tomar en consideración los intereses de los actores nacionales y locales, antes que los externos.

A nivel de la economía en su conjunto (nivel macroeconómico) los gobiernos se están dando cuenta que el fomento del comercio y la inversión extranjera como instrumentos de transferencia de conocimientos debe venir acompañado de exigencias de asimilación y aprendizaje tecnológico local para que estas experiencias sean más productivas (Cassiolato $y$ Vitorino, 2009). El comercio y la inversión por si solas no necesariamente conducen a la transferencia u absorción de conocimientos a nivel local. El gobierno y las empresas deben exigir en contrapartida a los inversionistas extranjeros algún tipo de aprendizaje y transferencia tecnológica. El gobierno debe además impulsar los centros de transferencia y difusión de conocimientos y políticas públicas que proveen fondos (para licenciar o adquirir tecnologías, aprender a absorber conocimientos o atraer capital de riesgo), concedan subvenciones, movilicen e intercambian talentos, pongan a disposición información, desarrollen infraestructura tecnológica y promuevan las vinculaciones entre empresas y el mundo científico tecnológico.

Para elevar la productividad de todo el sistema económico es necesario articular y generar sinergias y externalidades que propulsen la transferencia de tecnologías y el progreso del sistema en su conjunto. Se trata de articular vínculos y fuerzas propagadoras que difundan los nuevos conocimientos y eleven la productividad del sistema (Roca, 2011a: 57 y 2012a). En este sentido, el fomento de encadenamientos y redes verticales y horizontales, multi disciplinas y multi sectores, y el fomento de clusters y conglomerados abrirán las oportunidades de transferencia y la absorción de conocimientos en forma masiva.

A nivel internacional, diversos estudios han demostrado que los contratos tecnológicos y la transferencia de tecnología están generalmente amarrados a una serie de condicionamientos y restricciones de las transnacionales que limitan el desarrollo de otros sectores e industrias. Existe por ejemplo, muchos contratos en donde transfieren la tecnología en bloque y no permiten abrirla; obligan a importar insumos, equipos y piezas de repuesto, limitan la competencia, exigen garantías, restringen las ventas de los productos en otros mercados en el exterior, se apoyan en una utilización excesiva de personal calificado extranjero, e inclusive restringen la libertad de acción de los gobiernos en relación a las políticas aduaneras, fiscales, tributarias y cambiarias y aquellas referidas a la inversión y el comercio En este aspecto, la Conferencia de las Naciones Unidas para el Comercio y el Desarrollo-por sus siglas en inglés (UNCTAD) (UNCTAD, 1975). Esto lleva a la necesidad de aprobar políticas económicas que restrinjan los comportamientos anticompetitivos de las empresas internacionales. 
La UNCTAD fracasó en su intento en los 80 's de aprobar un Código de Ética que restrinja las prácticas anticompetitivas y nocivas de la transferencia de tecnología en el mundo, teniendo que contentarse en enfocar su trabajo en la construcción de capacidades tecnológicas para que los países en vías de desarrollo aprovechen mejor las oportunidades existentes (UNCTAD, 2004).

De otro lado, la Organización Mundial de Comercio (OMC) aprobó en 1994, el Acuerdo Mundial de Propiedad Intelectual relacionado al Comercio, TRIPS, indicándose que este debería contribuir a la promoción de la innovación y a la transferencia y diseminación de la tecnología. Los países desarrollados se comprometieron en forma vinculante (a cambio de la aprobación del TRIPS) a proveer incentivos a sus empresas e instituciones para inducir la transferencia de tecnología a los países menos desarrollados a fin de crear una sólida base tecnológica en estos países (Arts. 7 y 66.2 del TRIPS). Casi 20 años después no se conoce del impacto general del TRIPS en la transferencia de tecnologías y en desarrollar sólidas bases tecnológicas en los países en vías de desarrollo. Los reportes anuales que los países desarrollados están obligados a entregar al Consejo del TRIPS no muestran mayor impacto. La mayoría de países desarrollados incumple la legislación internacional (Moon, 2011).

Por último, la Organización Mundial de Propiedad Intelectual (OMPI) que administra diversos acuerdos mundiales de propiedad intelectual y dedica una significativa parte de su presupuesto a proveer asistencia técnica a los países en desarrollo para promover la propiedad in- telectual, lamentablemente no está apoyando proyectos y programas que disminuyan las brechas tecnológicas entre países desarrollados y en vías de desarrollo, ya que la mayor parte de su cooperación técnica refuerza y extiende los derechos de propiedad intelectual de los actuales tenedores (principalmente empresas y personas de países desarrollados) sin contribuir a la generación y transferencia de tecnologías a los países en vías de desarrollo (Deere y Roca, 2011).

\section{Transferencia de tecnología en el Perú}

En la primera parte de esta sección se resume la situación global de la transferencia de tecnología en el Perú, y en la segunda se analizan los principales factores que afectan la transferencia de tecnología a nivel de las empresas y organizaciones.

\subsection{Situación global}

No existen estudios ni encuestas integrales que evalúen el alcance y la extensión de la transferencia de tecnologías en el Perú. Un trabajo de hace ya más de una década (Warner, 2000) construye un índice de creatividad económica compuesto por tres sub-índices: uno de innovación, otro de starts ups y otro de transferencia tecnológica. En la evaluación de los países analizados se encuentra que los países de América Latina están mal en los 3 indicadores, en comparación con los países del Sud Este Asiático y los países desarrollados. La distancia es mayor en innovación y stars ups, que en transferencia tecnológica. Si uno individualiza al 
Perú, se está entre los peores en innovación (puesto 54/59) y starts ups (puesto $56 / 59$ ) mientras que en transferencia tecnológica le ganamos a un buen número de países de la región (puesto 40/59). Esto que pareciera premio de consuelo en transferencia tecnológica, pierde parte de sus efectos cuando se descubre que la definición de transferencia tecnológica se refiere principalmente a uso y no producción de tecnología; es decir lo que está diciendo es que el Perú fundamentalmente no produce sino usa tecnología importada, si se quiere en paquetes, auto-contenida, llave en mano, e incorporada en los bienes y servicios que consume y usa como bienes de capital. Grafica esta situación, que alrededor del $57 \%$ del total de importaciones y solo el $4 \%$ de las exportaciones del Perú, sean de bienes y servicios de mediana y alta tecnología (Roca, 2012b: 26) ${ }^{2}$.

Esta observación se corrobora en la información que emana de las encuestas sobre innovación hecha a grandes y medianas empresas en el 2000 y 2004 (Consejo Nacional de Ciencia y Tecnología (CONCYTEC, 2000 y 2004). Según la encuesta del 2000 , solo $9 \%$ de las empresas encuestadas invierten en tecnologías no incorporadas en bienes de capital. $Y$ de este $9 \%$, el $61 \%$ adquiere todos los servicios tecnológicos en el exterior, $20 \%$ tienen licencias tecnológicas, y el $19 \%$ lo hace a través del uso de marcas y servicios de estandarización y control de cali- dad del exterior (Kuramoto y Torero, 2009). De esta manera, se puede observar que el tipo de transferencia tecnológica que existe en el Perú no conlleva aprendizaje de la tecnología, transmisión de conocimientos, empoderamiento tecnológico, ni siquiera a la provisión de servicios tecnológicos dentro del país.

Las multinacionales transfieren la producción de tecnología a sus subsidiarias dentro de la propia empresa controlándola; y las empresas nacionales compran los bienes de capital del exterior en paquetes, llave en mano, en cajas negras y realizan sus servicios tecnológicos contratando empresas extranjeras. No existen muchas distribuidoras de bienes tecnológicos reconocidas instaladas en el Perú. Según un estudio de innovación en el sector agroindustrial (Huarachi et al, 2010 ), el $81.7 \%$ de las empresas del sector, introducen tecnologías que ya poseen otras empresas locales, lo que significa que la imitación es quizás una de los canales de mayor uso para transferir tecnologías en el sector. Muy pocas empresas manufactureras nacionales tienen maestranzas y talleres especializados de alta tecnología con tecnólogos y especialistas nacionales. Los esfuerzos que algunas empresas hicieron en la década de los 60 's, 70 s y 80 's se perdieron con la liberalización y el desmantelamiento de las políticas tecnológicas en los 90s. La decidida promoción del comercio y la inversión extranjera de los 90 's y 2000s, se buena parte de estos recursos no renovables, limitará su desarrollo (Roca 2011b:158). 
hizo sin exigir aprendizaje tecnológico, formación de recursos humanos y servicios de soporte tecnológico local, ni promoviendo encadenamientos, formación de conglomerados y transferencia de conocimientos y tecnología a la economía local.

Si ello ocurrió en las medianas y grandes empresas, ni qué decir en relación a la transferencia de tecnologías a las pequeñas y micro empresas. La mayoría de micro y pequeñas empresa trabaja con tecnologías artesanales o de muy baja calidad, no teniendo acceso a otras de mayor productividad (Chacaltana, 2003). Solo recientemente se notan algunos cambios en el segmento de las micros y pequeñas empresas especializadas en tecnologías de información y comunicación (TICs), y en algunos sectores económicos y servicios tecnológicos empresariales. Ello en parte es resultado de un cambio en la política tecnológica del gobierno a mediados de los 2000s con la creación de los Centros de Innovación y Transferencia Tecnológica para las pequeñas y micro empresas (CITES); y la iniciativa de algunos gremios empresariales que se adhirieron a esa iniciativa (Organización Económica para la Cooperación y el Desarrollo (OECD), 2011; UNCTAD, 2011).

La mayoría de universidades e instituciones del sistema de educación no están preparadas para transmitir tecnologías o servicios tecnológicos, dedicándose más bien a la transmisión de conocimiento formal y enseñanza básica y teórica general y en muchos casos de muy pobre calidad (OECD, 2011). Solo algunas universidades e instituciones como el Centro de Estudios Superiores de Formación Tecnológica (TECSUP) y Servicio Nacional de Adiestramiento en Trabajo
Industrial (SENATI) y unos pocos institutos y certificadoras nacionales ofrecen servicios de soporte tecnológico y control de pruebas y estándares. Los institutos públicos de investigación realizan investigación y desarrollo de baja calidad, tienen pocos recursos humanos de alto nivel y no se dedican apoyar la transferencia de tecnología a las empresas. Carecen además de visión estratégica, no tienen financiamiento y enfrentan conflictos de interés (Finnish Innovation Technology Group, 2011).

No obstante, algunos fenómenos aislados de difusión y transferencia tecnológica endógena están emergiendo en algunos sectores específicos, como por ejemplo gastronomía, franquicies, tecnologías de información y sistemas de soporte empresarial. En la actividad gastronómica, por ejemplo, no solo se está difundiendo masivamente la tecnología en la preparación de los platos, sino en los aspectos vinculados a la calidad del servicio, atención al cliente, y sus encadenamientos hacia adelante y hacia atrás: en la siembra y cosecha de los alimentos, los ingredientes y uso de los productos naturales, en el transporte y la cadena logística de aprovisionamiento, los vínculos con la industria del pre-cocido, el empacado, etc y hacia adelante con la industria turística y otros productos y servicios a la medida, hasta la exportación de cocineros, ingredientes y alimentos al exterior. Las vinculaciones entre cocineros, entre escuelas de cocina y entre autoridades gubernamentales es cada vez mayor; así como las interrelaciones entre todos ellos, incluyendo la cooperación técnica con el exterior y eventos internacionales donde se transmiten conocimientos y se 
atraen personalidades mundiales de la cocina. Todo ello está propulsando un significativo y poderoso cluster donde se difunde y transmite arte, recetas y conocimientos, se eleva la calidad y se agrega valor, aumentando los ingresos y la productividad a estas industrias.

Otro sector donde aparece el desarrollo de un tipo limitado de transferencia tecnológica es el de las franquicias. Existe actualmente en el país alrededor de 300 contratos de franquicies, el $60 \%$ de ellas extranjeras, principalmente en los rubros restaurantes, estética, belleza, salud y joyería y ellas transfieren conocimientos y tecnologías a través de licencias y especificaciones técnicas que elevan la calidad de los servicios ${ }^{3}$.

\subsection{Experiencias empresariales de transferencia o absorción de tecnologías en el Perú}

A pesar de que en realidad se conoce muy poco y hay pocos estudios a profundidad sobre experiencias de trans- ferencia de tecnologías en el Perú, la investigación realizada para escribir este artículo ha revisado 11 estudios de casos específicos de experiencias peruanas que han intentado procesos de absorción y transferencia de tecnologías o innovación ${ }^{4}$. Cuatro de estos casos proceden del sector agroindustrial: Central Piurana de Banano Orgánico (CEPIBO), Central Piurana de Cafetaleros (CEPICAFE), Pisco Payet, y, Agroindustrias de Exportación; una del sector ganadero: caso Micaela Bastidas; otra del sector maderero: Cite Madera; dos del sector textil: caso Exportador Textil y Confecciones y caso Innovación de Procesos de Producción; dos del sector salud: caso Hersil y caso del Instituto Nacional de Salud; y, uno del sector de tecnologías de información: caso TICs ${ }^{5}$.

Conforme se fueron revisando cada uno de estos 11 casos se fueron inicialmente clasificando los principales factores que favorecieron o restringieron la transferencia o absorción de tecnologías. Dado que los estudios no tuvieron una

4 Se revisaron estos casos porque no se encontraron -en una revisión somera- otros trabajos publicados de experiencias de transferencia de tecnologías o innovación en el Perú.

5 La mayoría de los casos (9 de los 11 analizados) son el resultado de un programa de investigación relativamente reciente del CIES (un consorcio de investigación a la que pertenecen varias universidades del Perú) llevado a cabo en el 2010, apoyado por la cooperación Canadiense, en donde se encargaron diversos estudios a distintos autores para estudiar los procesos de innovación y transferencia tecnológica. La investigación no tuvo una metodología común y se dejó libertad a los autores a escoger los casos o sectores. La mayoría de los estudios son descriptivos, se basan en encuestas, cada una diferente a la otra, según el enfoque de cada autor, y que luego fueron compiladas y publicadas "en bruto" por el CIES. La razón de este programa de investigación era contribuir a entender que elementos gravitaban en el éxito o fracaso en la introducción de innovaciones o procesos de transferencia tecnológica. La lista de cada uno de los casos se presenta en la bibliografía de casos que se encuentra al final de este artículo antes de la bibliografía general. 
metodología común, resultaron una gran cantidad de factores o categorías. Del análisis comparativo de los factores encontrados se fueron reduciendo y agrupando los factores en ocho principales categorías, que a nuestro criterio reflejaban la praxis y vivencia de estas experiencias. No todas las categorías están presentes en cada caso, ya que los factores tienen distinta predominancia y peso según la experiencia ${ }^{6}$. Las ocho categorías que agruparon a todos los factores fueron: 1) capacidades individuales, 2) capacidades empresariales, 3) fallas de información, cooperación y coordinación, 4) vinculaciones y conexiones externas $y$ con otros actores, 5) infraestructura, 6) financiamiento, 7) instituciones, y, 8) fuerzas propagadoras y sistémicas. Los casos muestran como en algunos casos se agiliza y en otros se limita la transferencia y absorción de tecnologías, dependiendo de las características del producto, las capacidades de las personas, la arquitectura institucional e infraestructura existente, las vinculaciones externas, las carencias organizacionales de la empresa y las fallas del mercado y fuerzas propagadoras y sinérgicas existentes.

En el Cuadro 1, dividido en los sectores ganadero, maderero, textil, salud y sofware, se sintetiza y presenta los principales resultados de la investigación. En términos generales se nota que en varios de los casos se repiten algunos de los factores que afectan los procesos de transferencia tecnológica. Se necesita por ejemplo, facilitar el aprendizaje y capacitación individual del personal (Casos sectores agrícola, ganadero y maderero) pero también la empresa debe organizarse mejor y aprender a detectar sus necesidades tecnológicas y diseminar los conocimientos a equipos de ingenieros $y$ desarrolladores (Caso CEPIBO y Pisco Payet). Las fallas de información y cooperación son a menudo un obstáculo importante, como se menciona en los casos del sector textil donde comportamientos egoístas de no compartir conocimientos retardan los procesos de transferencia y difusión de las tecnologías. Al revés en el caso de las cooperativas de Café (CEPICAFE), la asociatividad es una virtud para el intercambio fluido de buenas prácticas entre los cooperativistas. Las conexiones y vinculaciones externas a la empresa juegan un rol esencial en los casos de CEPICAFE, CEPIBO, Agroindustrias, Pisco Payet, sector maderero, Hersil, y la industria de TICs. La existencia de laboratorios, materiales, y certificaciones juegan un rol positivo en los casos del sector maderero, el sector agroindustrial y el software. Al contrario, su carencia en la industria de productos naturales (sector salud) limita la estandarización de los principios activos y la homogenización de la materia prima, lo que afecta los procesos de transferencia de tecnología. 


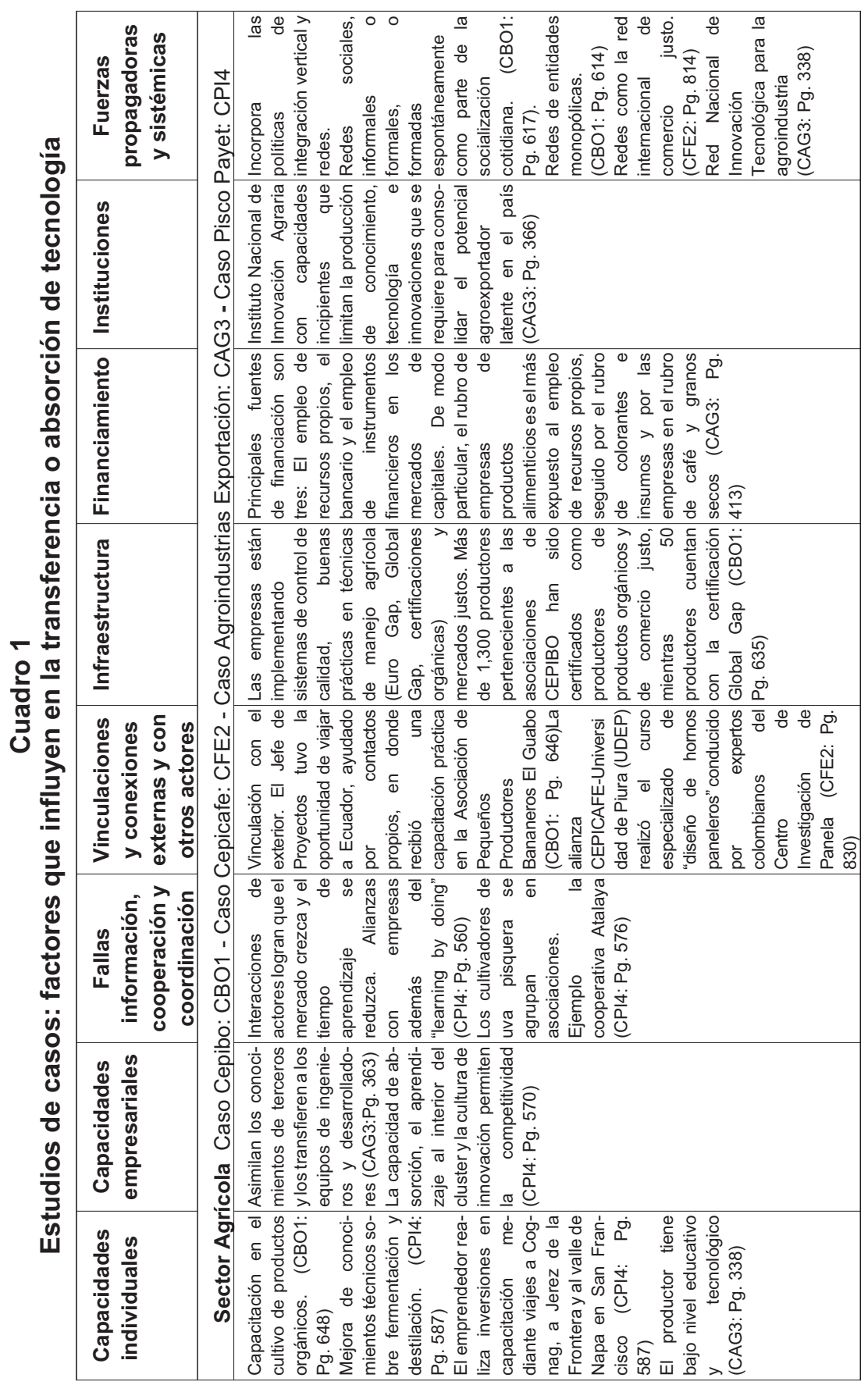




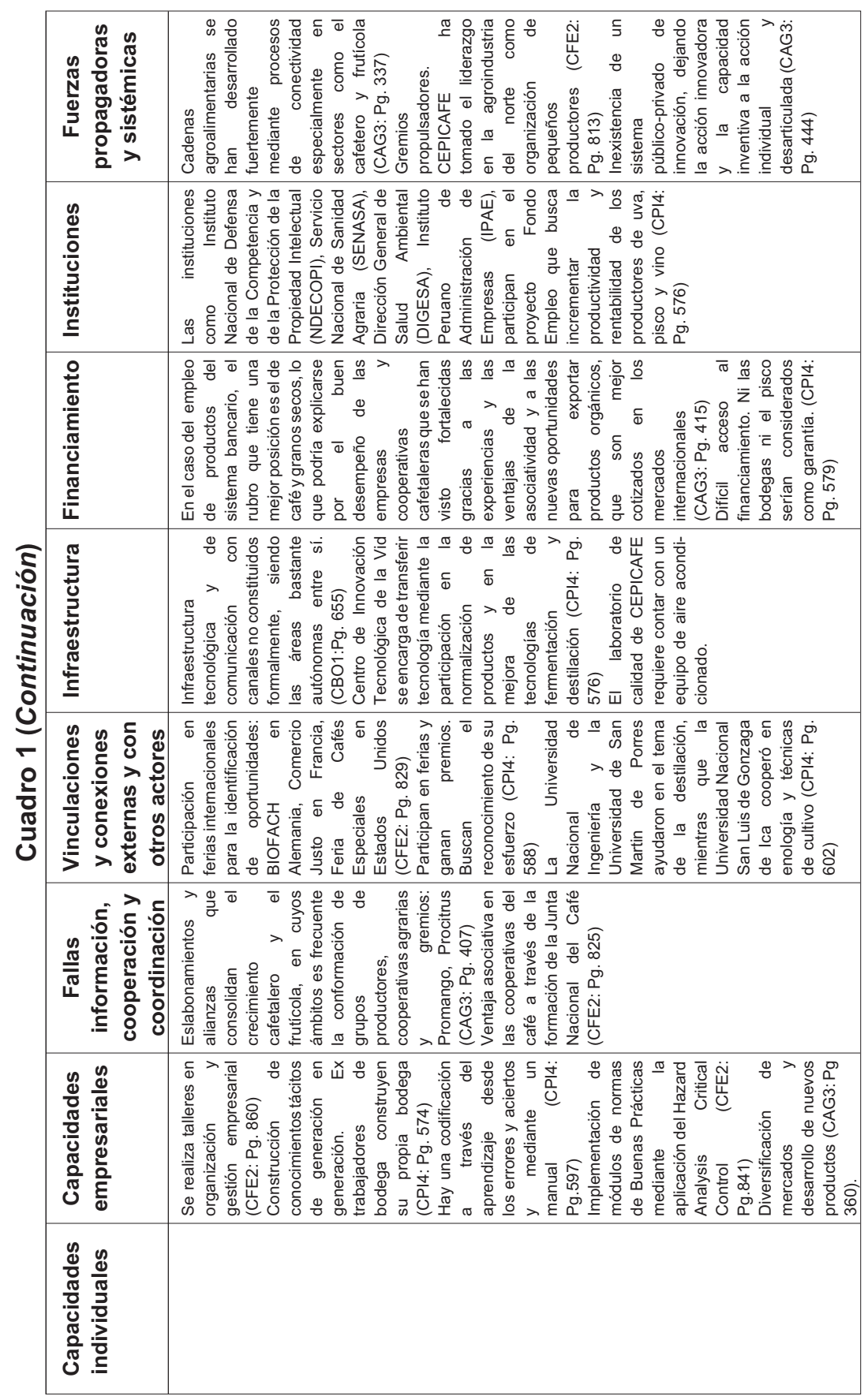




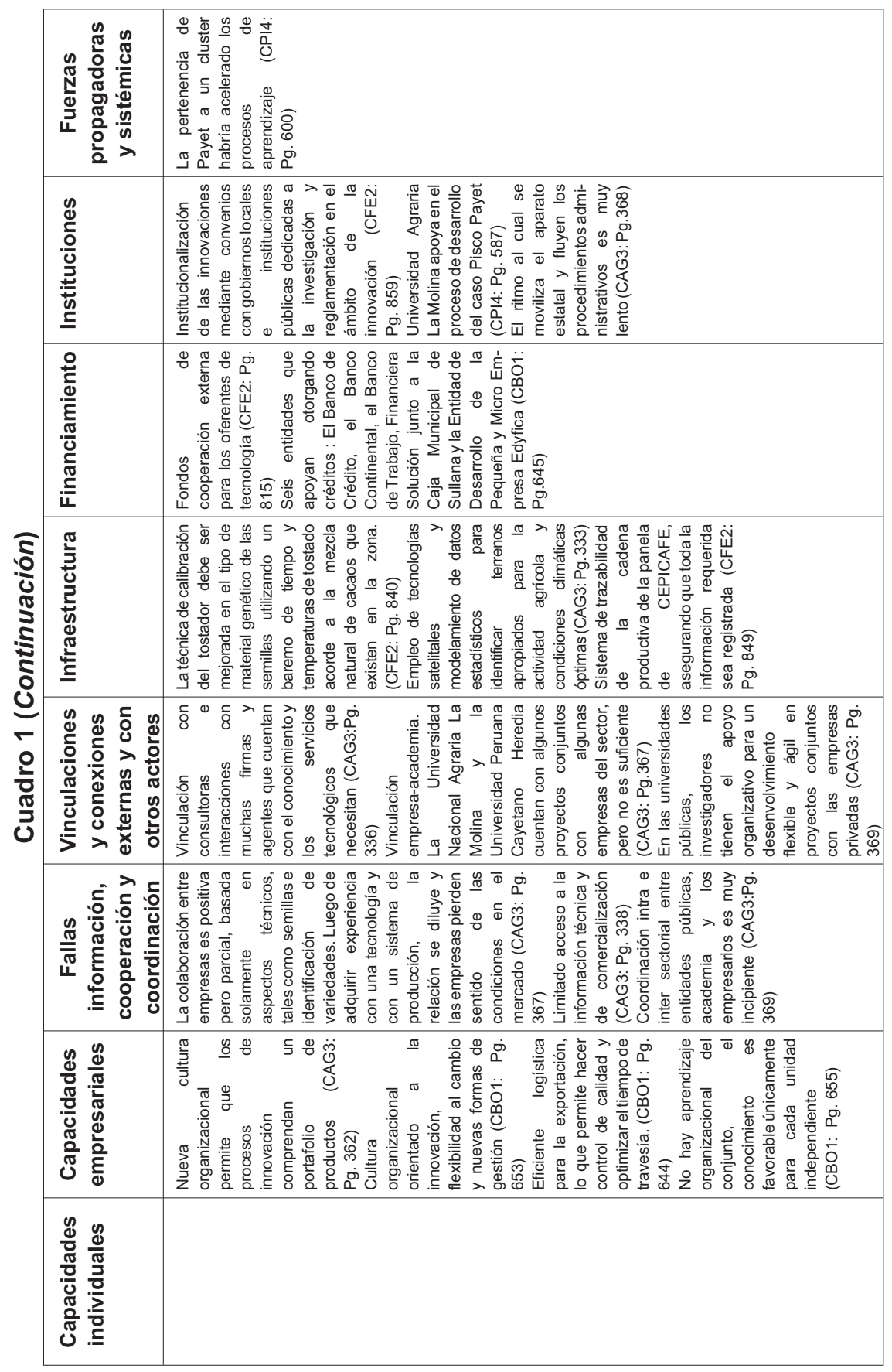




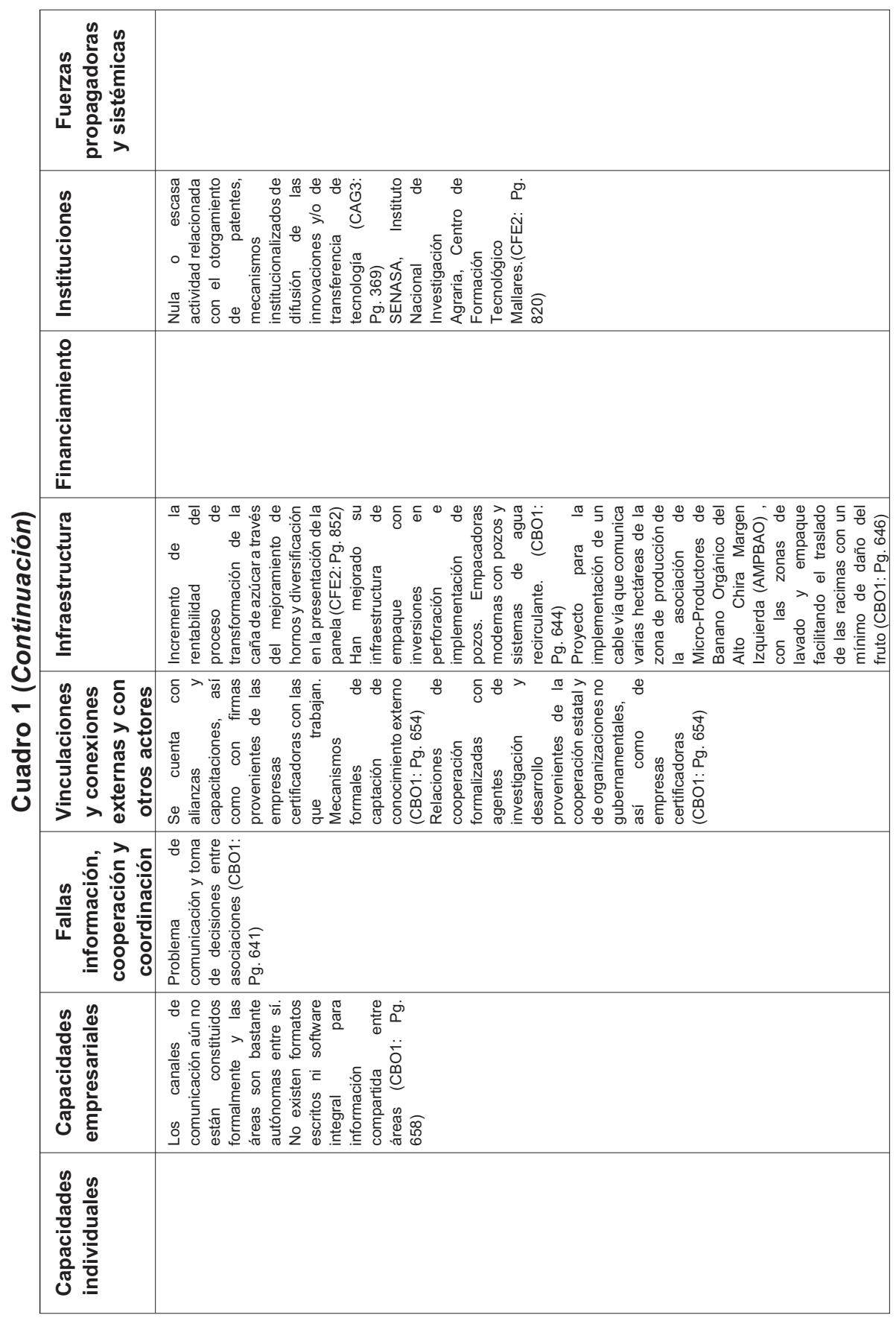


Políticas y factores que contribuyen a la transferencia de tecnología...

Roca T., Santiago

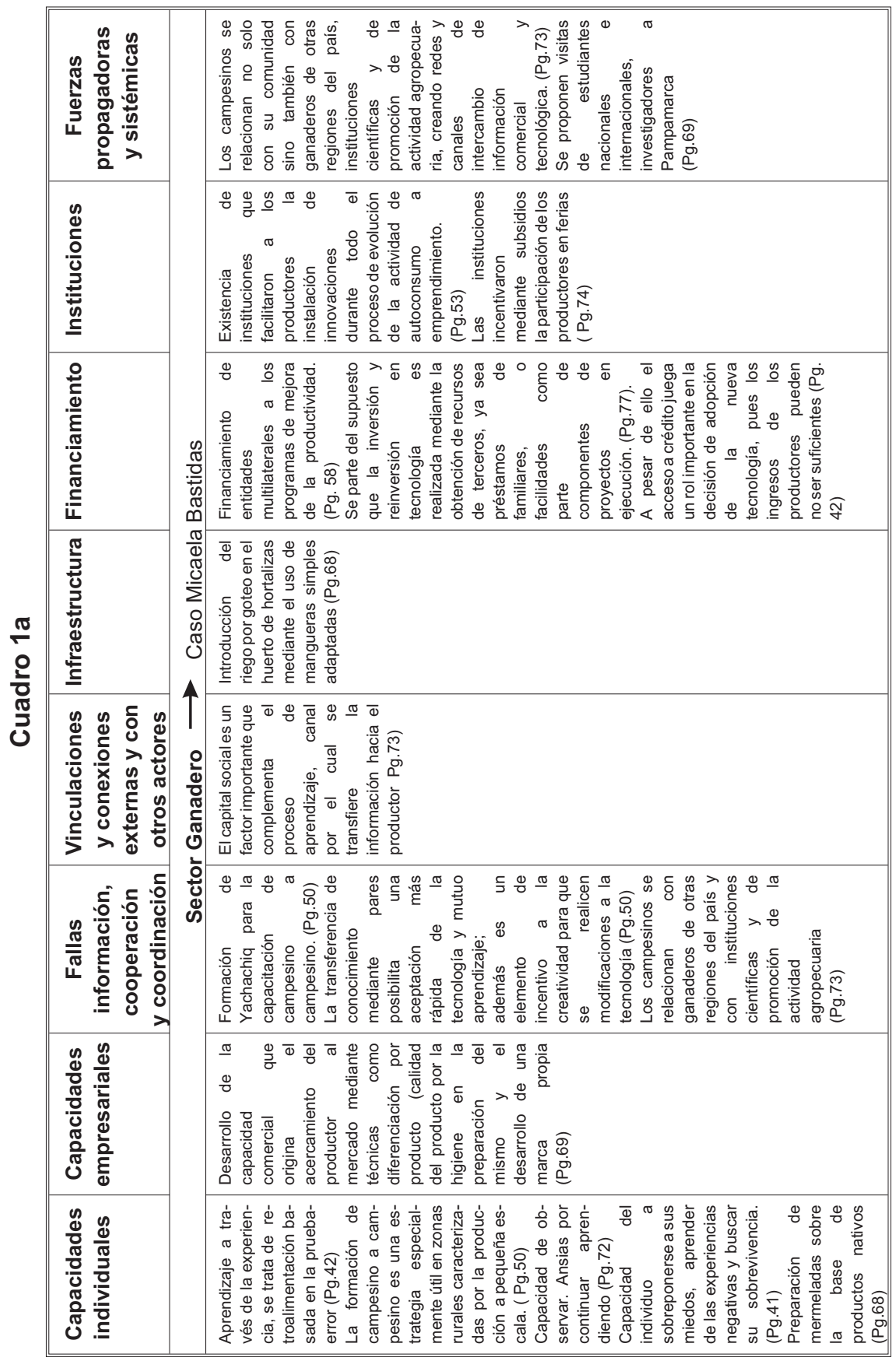




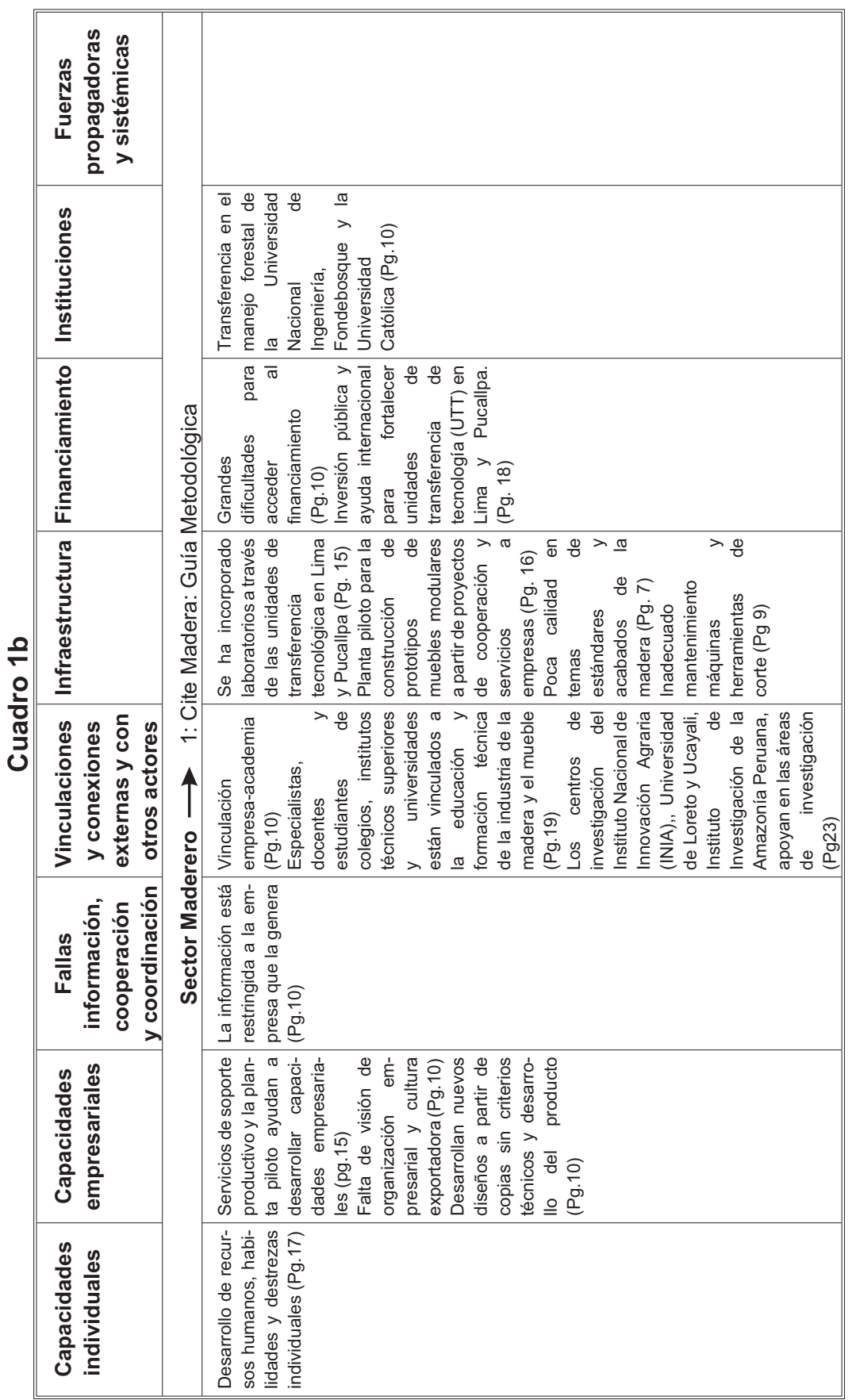




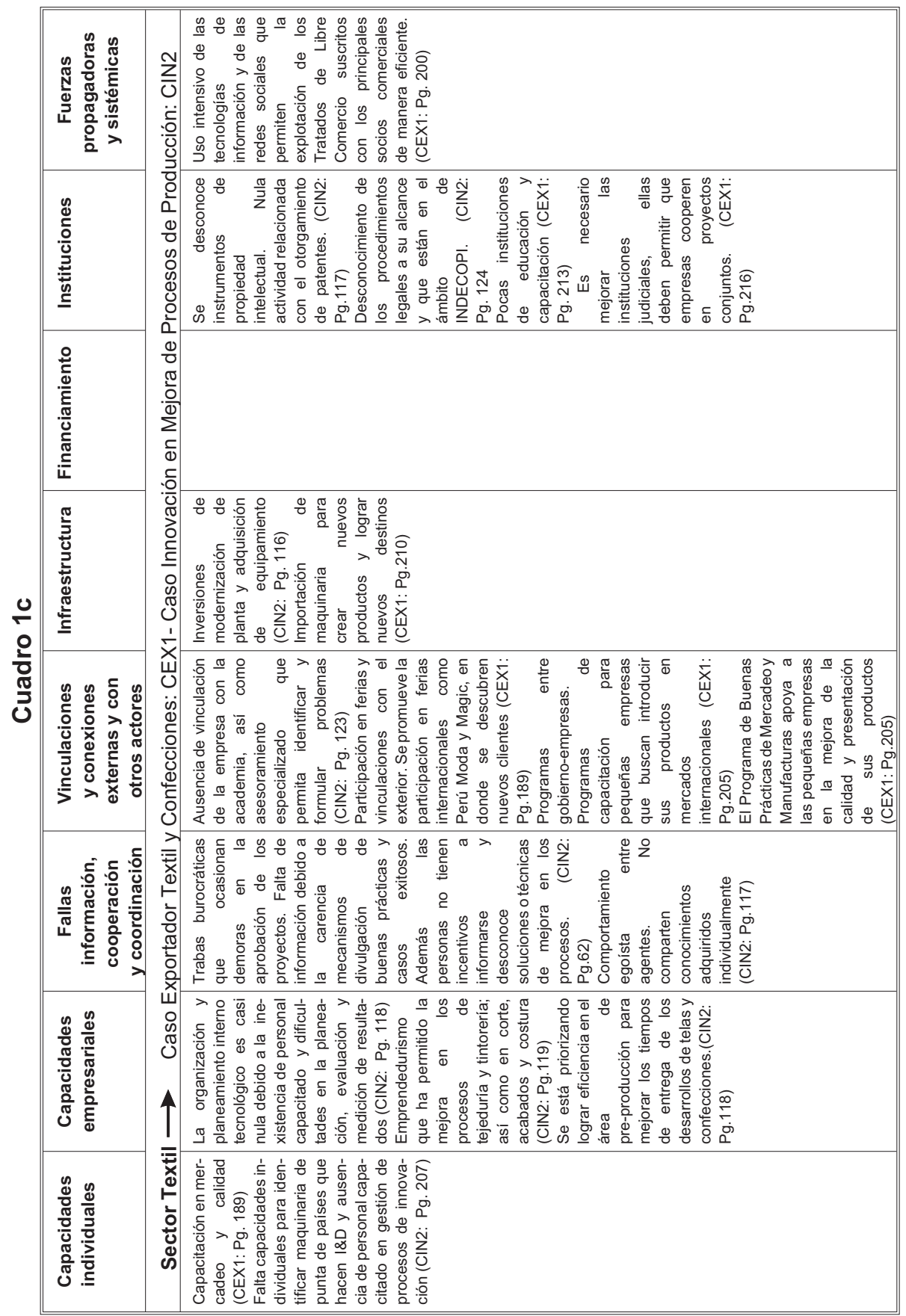




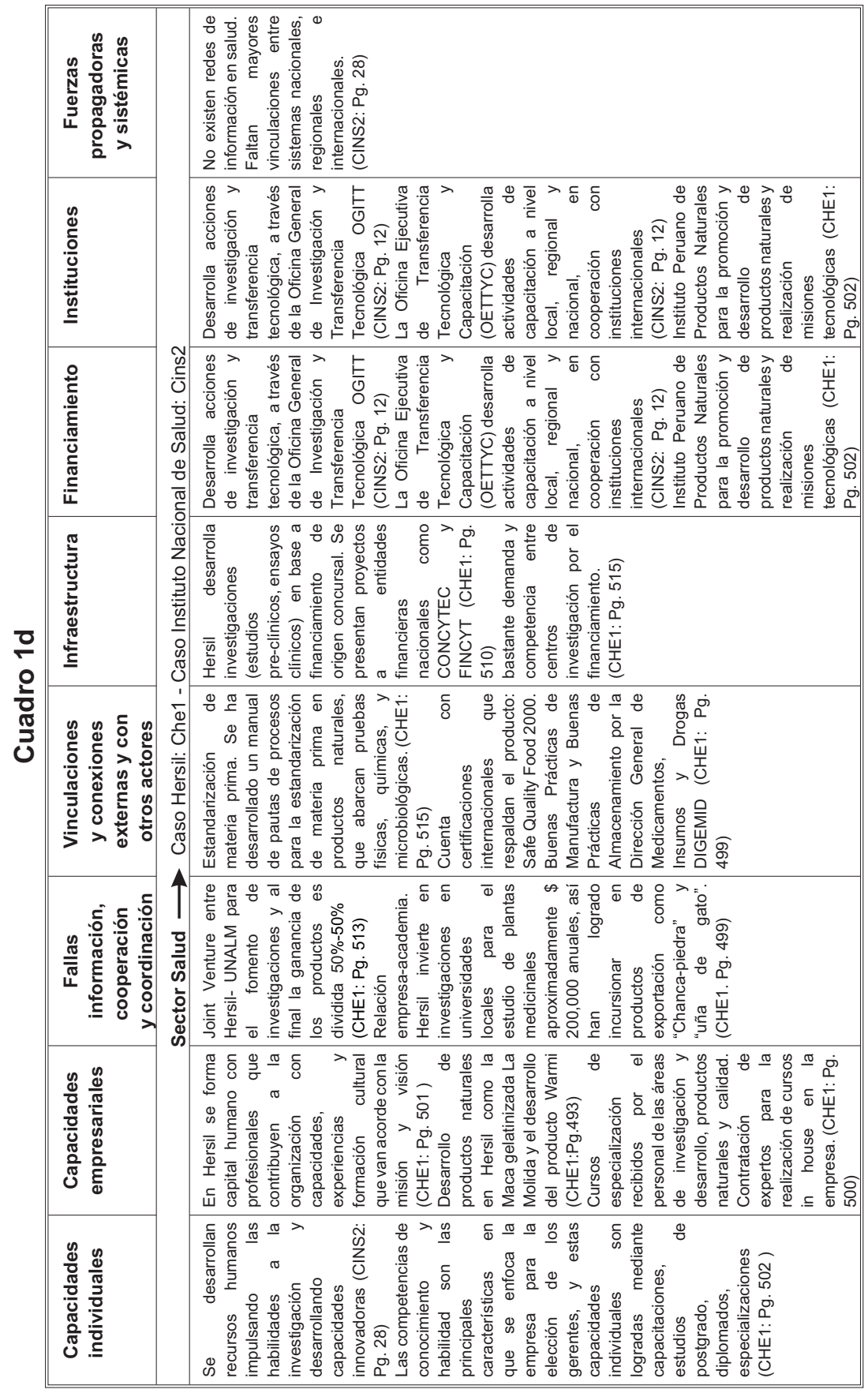


Políticas y factores que contribuyen a la transferencia de tecnología...

Roca T., Santiago

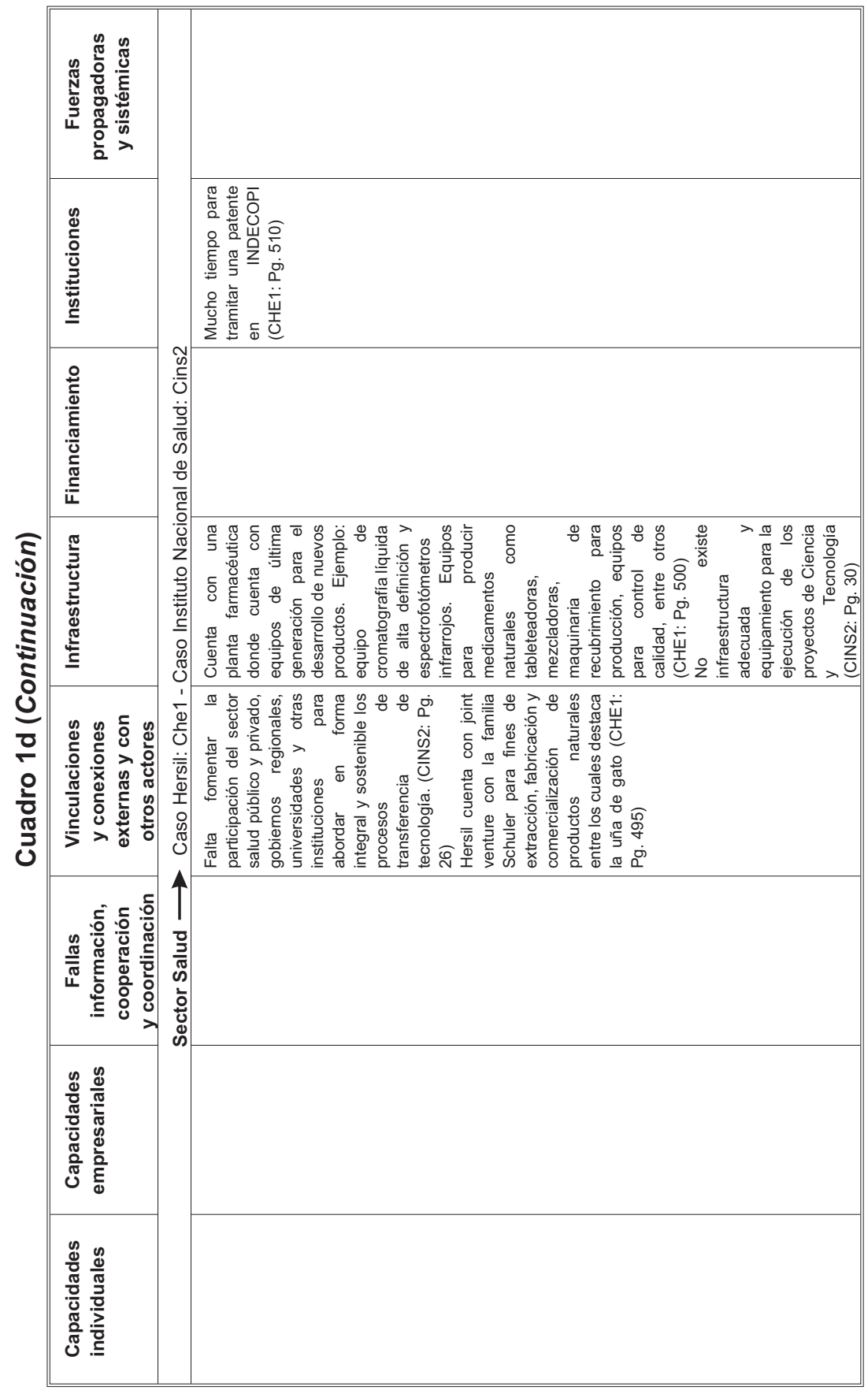




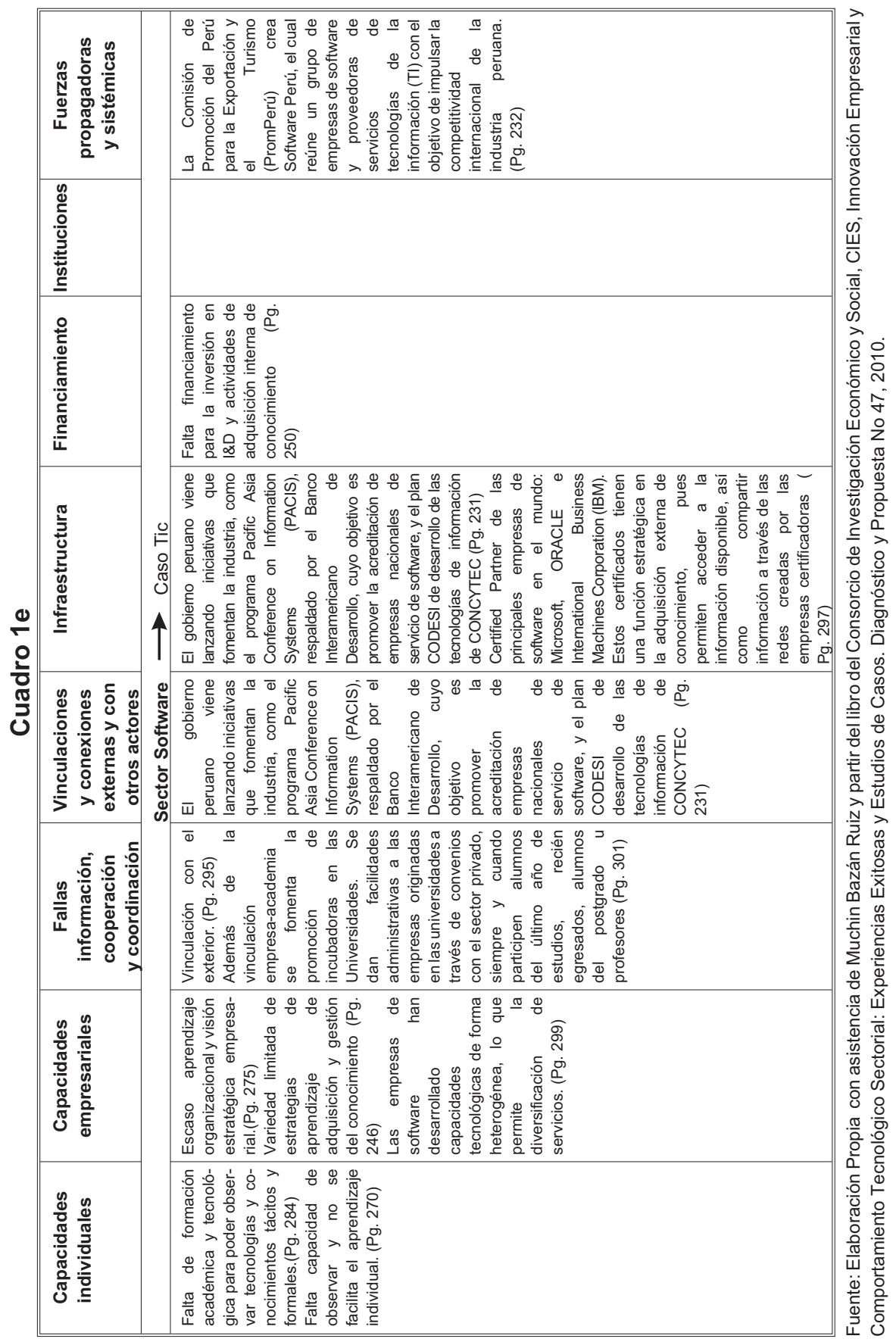


La escasez de fondos y de fuentes de financiamiento es otro factor presente, aunque es importante señalar que los requerimientos de acceso a estos fondos son más efectivos cuando refuerzan o exigen compromisos relativos a los otros factores que afectan los procesos de transferencia de tecnologías. Por ejemplo, algunos fondos otorgan financiamiento exigiendo asociatividad, capacidades específicas, vinculaciones con el exterior, organicidad, información u alianzas, mientras otros no exigen nada y son más laxos, lo que podría aumentar el riesgo de fracaso si no satisfacen los otros condicionamientos que influyen en la transferencia de tecnologías.

El rol de las instituciones públicas, privadas, universidades y organizaciones no gubernamentales resulta muy valorado en la mayoría de los casos. En Pisco Payet, y Cite Madera, por ejemplo, juegan un rol importante en difundir las tecnologías y buenas prácticas. Las universidades participan en alianzas (caso Hersil, y caso Agroindustria de Exportación); el Instituto Nacional de Salud por su lado realiza sus propias investigaciones.

La creación y anexión a redes y sistemas de información fortalecen las fuerzas propagadores de las experiencias como es característico en la industria textil exportadora, en el caso TICs y entre los productores de banano orgánico (CEPI$\mathrm{BO}$ ); resultando en una limitante en el caso del Instituto Nacional de Salud.

\section{A modo de conclusión}

El Perú es uno de los países en vías de desarrollo que no tiene una política tecnológica clara y definida. La falta de visión de sus gobernantes y la creencia ideológica impulsada desde hace más de 20 años, de que las empresas en forma libre y el mercado por si solo definen la especialización productiva y la trayectoria tecnológica, han hecho que el Perú sea predominantemente un comprador de casi toda la tecnología productiva que utiliza. Sea que la tecnología venga incorporada en los bienes de capital, procesos productivos o insumos, generalmente las empresas peruanas despliegan muy poco esfuerzo para aprender y conocer acerca de la misma. La aproximación hacia la tecnología es tan pasiva, que un contingente importante de empresas ni siquiera se preocupa en absorber los conocimientos mínimos necesarios para mantener o reparar los equipos, los cuales dependen exclusivamente de servicios del exterior. Grafica esta situación, que alrededor del $57 \%$ del total de importaciones y solo el $4 \%$ de las exportaciones del Perú, sean de bienes y servicios de mediana y alta tecnología (Roca, 2012b: 26). La viabilidad futura de este tipo de economía depende de la capacidad de exportar mayores cantidades de bienes simples y primarios, lo cual ahora es posible, pero a la larga al ser una buena parte de estos recursos no renovables, limitará su desarrollo (Roca 2011b:158).

El Perú debe tomar determinaciones fundamentales para su desarrollo. De los países tecnológicamente más desarrollados tiene que absorber conocimientos en las áreas donde pueda sustituir servicios y productos tecnológicos del exterior, y crear a la vez nuevas tecnologías en las áreas donde tenemos algunas ventajas competitivas. La absorción y 
transferencia de tecnologías se transforma en verdad en el pilar más importante del upgrading tecnológico doméstico de la estructura productiva, quizás más relevante aún, que la creación y generación de nuevas tecnologías y la inversión en investigación y desarrollo. Si se logra masivamente absorber conocimientos y tecnologías del exterior se va a poder aumentar en forma progresiva el contenido tecnológico nacional y el valor doméstico de los productos y servicios que se producen.

En la segunda sección de este artículo se ha escudriñado algunas de las principales políticas públicas y factores que influyen en la transferencia y absorción de tecnologías. La principal de ellas es la determinación estratégica y voluntad deliberada de todos los agentes: gobierno, empresas nacionales y tecnólogos, que la transferencia de tecnología es necesaria para añadir valor doméstico a las actividades económicas y que ella debe estar siempre adelante y ser filtro en la ejecución y determinación de las políticas públicas del país. A diferencia de lo que argumentan los fundamentalistas del libre mercado (en cuanto a que las tecnologías aparecen por la libre determinación de las fuerzas de oferta y demanda) todos los países tecnológicamente desarrollados han tenido una activa y consciente actuación del Estado en la creación, transferencia y absorción de tecnologías. En este sentido en vez de hipotecar el país al comercio y la inversión ex- tranjera como única fuente del crecimiento, hay que buscar en el Estado un balance interno-externo que promueva el comercio e inversión pero en un marco donde lo prioritario sea la creación y transferencia de tecnología.

Se tiene que comprender que el tema de la propiedad, control y regalías que está detrás de la tecnología hace que la transferencia de la misma requiera también del activo interés y determinación de aquellos interesados, y que por lo tanto las políticas públicas deben orientarse a facilitar este encuentro en favor de los nacionales. La transferencia no es una concesión espontánea de los tenedores de la tecnología. Como se indicó los tenedores, procuraran por el contrario ocultarla (vender el bien pero no transferir la tecnología), agruparla en bloques, amarrarla a insumos y piezas que ellos mismos controlan, impidiendo la competencia, y exigiendo una serie de condicionamientos de garantías, financiamiento y otros, a su beneficio. $Y$ las empresas nacionales no tienen ante quién, ni cómo defenderse. Nadie evalúa en el Perú la contribución y restricciones que traen los contratos de licenciamiento, asistencia y servicios técnicos ni aquellos de ingeniería básica y de detalle. No hay autoridad ni oficina pública que fomente la transferencia de tecnología y ni siquiera se cuenta con un registro público exigible de contratos de tecnología que sirva de fuente de información y aprendizaje ${ }^{7}$. La Oficina 
de Patentes indica que la ley peruana no obliga a la inscripción de estos contratos y estos en todo caso solo son opinables frente a terceros. No existe entonces política pública ni instrumentos para sancionar prácticas anticompetitivas en los contratos tecnológicos.

De otro lado, en el Perú no existe una política industrial que focalice e inclusive que coordine la inversión en pro de la transferencia de tecnología. No existen programas de compras estatales, asociaciones público-privadas como instrumentos para desarrollar tecnologías y programas que fomenten la creación de valor, el upgrading, la comercialización de tecnologías y la priorización de compras de bienes de capital y productos tecnológicos en sectores prioritarios. Falta desarrollar los autodiagnósticos de gestión tecnológica, la prospectiva tecnológica y los calces de oferta y demanda de tecnologías. Igual de necesario resulta la reforma del sistema educativo nacional y de aprendizaje y los estímulos para la retención y atracción de personas con habilidad ingenieril y tecnológica así como para gerenciar y negociar contratos tecnológicos.

No obstante, las políticas públicas no son suficientes para que prospere la absorción y transferencia de conocimientos y tecnologías en el país. Se necesita que las empresas, las instituciones y las personas se aboquen a enfrentar las 8 grandes categorías de problemas que enfrentan los procesos de absorción y transferencia de tecnologías detectados en los estudios de casos revisados en la tercera sección de este trabajo (ver Tabla 1). El fortalecimiento de las capacidades de los individuos y de las empresas para aprender es uno de los principales cuellos de botellas existentes, incluida la cultura de proveer información, el trabajo en equipo, la cooperación y coordinación; ni qué decir de la necesidad de apertura y conexiones con el exterior, la creación de infraestructura básica, el acceso al financiamiento y la promoción de fuerzas sistémicas y propagadoras, como las que están desenvolviéndose en el sector gastronómico y de tics.

Tan importante como lo anterior es el fortalecimiento de la institucionalidad: ministerio de CTI, agencias y sistemas que propulsan la intermediación tecnológica, el sistema nacional de calidad y competitividad, la propiedad intelectual y las instituciones que reducen el riesgo, aseguran y defienden la libre competencia (Ministerio de Educación del Perú, 2012). Especial consideración debe tener dentro de esta institucionalidad, la evaluación de los institutos de investigación y la carrera de los investigadores como instrumentos que meriten el logro de objetivos y el aumento de la productividad (Montoya, 2011).

La cancha de la ciencia, tecnología e innovación ha sido trazada en los

nes. La desaparición de la Comisión Nacional de Inversiones y Tecnologías (CONITE) a comienzos de los 90's transfirió esta función a las Oficinas de Propiedad Intelectual del INDECOPI, pero el art 39 del DL 1033 del 2010 promulgado en el marco del TLC con Estados Unidos interpreta que la inscripción de estos contratos no es obligatoria. 
acuerdos internacionales de libre comercio y en menor grado en los organismos multilaterales internacionales por los países tecnológicamente más desarrollados, obviamente en su propio beneficio. Los países en vías de desarrollo tienen todavía sin embargo algunos márgenes de maniobra que deben saber activar. El Perú debería exigir a la UNCTAD que reactive acuerdos que no solo construyan capacidades tecnológicas sino restrinjan las prácticas anticompetitivas y evite barreras que impiden el acceso a la tecnología. A la Organización Mundial de Comercio, OMC, el Perú le debe exigir que los países desarrollados cumplan con los art 7 y 66.2 del Acuerdo Mundial de Propiedad Intelectual, TRIPS (administrado por la OMC), que los obliga a proveer incentivos a sus empresas e instituciones para que induzcan la transferencia de tecnología a los países en vías de desarrollo (Moon, 2011). Y a la Organización Mundial de Propiedad Intelectual, OMPI, el Perú le debe exigir que destine los ingentes recursos que recaba de los fees por el registro de derechos de propiedad intelectual, en beneficio de proyectos y programas que efectivamente reduzcan las brechas tecnológicas entre países desarrollados y aquellos en vías de desarrollo (Deere y Roca 2011).

\section{Referencias bibliográficas}

Afriyie, Kofi (1988). A Technology Transfer Methodology for Developing Joint Production Strategies in Varying Systems. Cooperative Strategies in International Business, Joint Ventures and Technology Partnerships between Firms, Contractor, F y Lorange, $\mathrm{P}$, Lexington Books, pp. 81-95.
Baranson, Jack (1970). Technology Transfer Through the International Firms. American Economic Review, Año $60, N^{\circ} 2$, American Economic Association, pp. 435-440.

Cassiolato, José y Vitorino, Virgínia (2009). BRICS and Development Alternatives: Innovation Systems and Policies, Estados Unidos, Anthem Press.

Chacaltana, Juan (2003). Public Policy and Employment in Micro and Small Enterprises in Perú. Seed Working Paper No 56, Switzerland, International Labor Office.

Chesnais Francois (1986). Science, Technology and Competitiveness. STI Review, N¹, Paris, OECD, pp. 85-129

CONCYTEC (2000). Encuesta Nacional sobre Ciencia, Tecnología e Innovación Tecnológica, Lima.

CONCYTEC (2004). Encuesta Nacional sobre CTI, Lima. http://portal.concytec. gob.pe/index.php/concytec/areasdela-institucion/politicas-y-planes/indiadores-ciencia-tecnologia-innovacion/ encuesta-cyt/resultados-encuesta-ciencia-tecnologia-innovacion-tecnologica-204.html, 30 de agosto 2013.

Contractor, Farok y Lorange, Peter (1988). Why should firms Cooperate?: The Strategy and Economic Basis for Cooperative Ventures. Cooperative Strategies in International Business, Joint Ventures and Technology Partnerships between Firms, Contractor, $\mathrm{F}$ y Lorange, $\mathrm{P}$, Lexington Books, pp. 3-30.

Decreto Legislativo 1033: Organización y Funciones del INDECOPI, 24 Junio 2008.

Deere, Carolyn y Roca, Santiago (2011), An External Review of WIPO Technical Assistance in the area of Cooperation for Development, http://www.wipo.int/ meetings/en/doc_details.jsp?doc_id= 182842, 30 agosto 2013. 
Finnish Innovation Technology Group (2011). Diagnóstico del Desempeño y Necesidades de los Institutos Públicos de Investigación y Desarrollo del Perú, Perú

Gestión, 06/11/2012, “Franquicias en el Perú facturarán más de US $\$ 1,000$ millones al cierre del año.", Lima, Perú

Harris, Robert y Ravenscraft, David (1991). The Role of Acquisitions in Foreign Direct Investment: Evidence from the US Stock Market. Journal of Finance, Año 46, $\mathrm{N}^{\circ} 3$ Estados Unidos, Blackwell Publishing, pp. 825-844.

Huarachi, Jorge; Larrea, Nelson; Vargas, Braulio; Heredia, Jorge y Yamakawa, Peter (2010). Diagnóstico del Estado de la Innovación en el Sector Agro Industrial de Exportación en el Perú. Innovación empresarial y comportamiento tecnológico sectorial: Experiencias exitosas y estudio de casos. Diagnóstico y propuesta. $\mathrm{N}^{\circ}$ 47, Perú, Consorcio de Investigación Económica y Social y Programa de Ciencia y Tecnología, pp. 307-447.

Huber, George (1991). Organizational Learning: The Contributing Processes and the Literature. Organization Science, Año 2, № 1, Estados Unidos, Institute for Operations Research, pp.88115.

Inkpen, Andrew (2000). Learning Through Joint Ventures: A Framework of Knowledge Adquisition. Journal of Management Studies, Año 37, $\mathrm{N}^{\circ} 7$, Estados Unidos, John Wiley \& Sons, Inc, pp. 1019-1043.

Kogut, Bruce y Zander, Udo (1993). Knowledge of the Firm and the Evolutionary Theory of the Multinational Corporation. Journal of International Business Studies, Año $24, N^{\circ} 4$, Inglaterra, Palgrave Macmillan Ltd, pp. 625-646.
Kuramoto, Juana y Torero, Máximo (2009). Public-Private Research, development and Innovation in Perú. Fueling Economic Growth: The Role of Public-Private Sector Research in Development, Canadá, International Development Research Centre, 1 era Edición, pp. 105-147.

Kuramoto, Juana. (2010). Practicas Exitosas de Innovación Empresarial y Comportamiento Tecnológico Sectorial. Innovación empresarial y comportamiento tecnológico sectorial: Experiencias exitosas y estudio de casos. Diagnóstico y propuesta. $\mathrm{N}^{\circ}$ 47, Perú, Consorcio de Investigación Económica y Social y Programa de Ciencia y Tecnología, pp. 13-35.

Mansfield, Edwin y Romeo, Anthony (1980). Technology Transfer to Oversees Subsidiaries by US Based Firms. Quaterly Journal of Economics, Año 95, N 4, Inglaterra, Oxford University Press, pp. 737-750.

Maskus, Keith (2004). Encouraging International Technology Transfer. Intellectual Property Rights and Sustainable Development, $\mathbf{N}^{\circ} 7$, Switzerland, International Centre for Trade and Sustainable Development- United Nations Conference Trade and Development.

Ministerio de Educación (2012). La Nueva Política e Institucionalidad para dinamizar la CTI en el Perú. Comisión Consultiva para la CTI.

Montoya, Modesto (2011). Políticas para impulsar la CTI en el Perú, Lima, Fondo Editorial San Marcos.

Moon, Suerie (2011), Meaningful Technology Transfer to LDCs: A Proposal for a Monotoring Mechanism for TRIPS Article 66.2. Policy Brief, $N^{\circ} 9$, Switzerland, International Centre for Trade and Sustainable Development. 
Organización Económica para la Cooperación y el Desarrollo (OECD) (2011). Review of Innovation Policy.

Pavitt, Keith (1985). Patent Statistics as Indicators of Innovative Activities: Possibilities and Problems, Scientometrics, Año 7, N 1 y 2, Estados Unidos, Kluwer Academic Publishers, pp. 77-99.

Reddy, Mohan y Zhao, Liming (1990). The International technology Transfer: A Review. Research Policy, Año 19, $\mathrm{N}^{\circ} 4$, Elsevier B.V., pp. 285-307

Roca, Santiago (2011a). Políticas para cerrar las Brechas de la Balanza de Conocimientos. Journal of Economics, Finance and Administrative Science, año $16, N^{\circ} 30$, Perú, Universidad ESAN, pp. 51-61

Roca, Santiago (2011b). La Balanza Comercial de Conocimientos: Guillen, Jorge y Roca, Santiago, Perú al 2021: Retos y Perspectivas para el Empresario, Argentina, Cengage Learning,

Roca, Santiago (2012a). Políticas Públicas para Gobernar, México, Pearson Educación.

Roca, Santiago (2012b). Especialización Tecnológica en el Comercio Exterior del Perú: Un Análisis Comparado con Corea, China, Colombia y México. Revista de Ciencia Sociales, Año 18, No 1, Venezuela, Universidad del Zulia, pp. 24-40

Sazali, Abdul; Raduan, Che; Suzana, Idayu (2012a). Defining the Concepts of Technology and Technology Transfer: A Literature Analysis. International Business Research, Año 5, N 1, Canadá, Canadian Center of Science and Education, pp. 61-71

Sazali, Abdul; Raduan, Che; Suzana, Idayu (2012b). Exploring the Technology Transfer Mechanisms by the Multinational Corporations: A Literature Review. Asian Journal of Social Science, Año $8, N^{\circ} 3$, Canadá, Canadian
Center of Science and Education, pp. 142-150.

Sazali, Abdul; Raduan, Che; Suzana, Idayu (2012c). Theoretical Perspectives Underlying Technology Transfer: A Literature Review. International Review of Business and Management, Año $7, N^{\circ} 2$, Canadá, Canadian Center of Science and Education, pp. 277-288.

Siddharthan, Natter (1992). Transaction Costs, Technology Transfer and In-House R\&D: A Study of the IndianPrivate Corporate Sector. Journal of Economic Behaviour and Organization, Año $18, \mathrm{~N}^{\circ} 2$, Estados Unidos,Elsevier B.V, pp. 265-271.

Speser, Phyllis (2006). The Art \& Science of Technology Transfer, Estados Unidos, John Wiley \& Son, Inc.

UNCTAD (1975). Principales Cuestiones que plantea la Transmisión de Tecnología a los Países en Desarrollo, Naciones TD/B/AC.11/10/Rev.2. Ginebra.

UNCTAD (2004). Beyond Conventional Wisdom in Development Policy: An Intellectual History of UNCTAD 1964-2004, New York \& Geneva

UNCTAD (2011). Examen de las Políticas de Ciencia, Tecnologia e Innovación, Perú

Wallander, Harvey (1979). Technology transfer and management in the developing countries: Company cases and policy analysis in Brasil, Kenya, Korea, Peru and Tanzania, Estados Unidos, Ballinger Publishing Company.

Warner, Andrew (2000). Economic Creativity. The Global Competitiveness Report 2000, Harvard University, Cambridge, Massachussets, pp28-38.

Zander, Udo y Kogut, Bruce (1995). Knowledge and the Speed of the Transfer and Imitation of Organizational Capabilities: An Empirical Test. 
The Organization Science, Año 6, $N^{\circ}$ 1, Estados Unidos, Institute for Operations Research and the Management Sciences, pp. 76-92.

\section{Referencias bibliográfícas de casos revisados}

\section{Sector Agrícola}

Caso CEPIBO (2010). Del Castillo, Carlos y Oviedo, Katia; Innovación tecnológica y organizacional en la central piurana de asociaciones de pequeños productores de banano orgánico CEPIBO. Innovación empresarial y comportamiento tecnológico sectorial: Experiencias exitosas y estudio de casos. Diagnóstico y propuesta, $\mathrm{N}^{\circ}$ 47, Perú, Consorcio de Investigación Económica y Social y Programa de Ciencia y Tecnología, pp. 609-804

Caso CEPICAFE (2010). Torres, Fidel; Prácticas tecnológicas y organizacionales exitosas de Cepicafe en la innovación del azúcar integral ecológica de exportación en el norte del Perú. Innovación empresarial y comportamiento tecnológico sectorial: Experiencias exitosas y estudio de casos. Diagnóstico y propuesta, $\mathrm{N}^{\circ}$ 47, Perú, Consorcio de Investigación Económica y Social y Programa de Ciencia y Tecnología, pp. 805-882.

Caso AGROINDUSTRIAS DE EXPORTACIÓN (2010). Huarachi, Jorge; Larrea, Nestor; Vargas, Braulio; Heredia, Jorge y Yamakawa, Peter; Diagnóstico del estado de la innovación en el sector agroindustrial de exportación en el Perú, Innovación empresarial y comportamiento tecnológico sectorial: Experiencias exitosas y estudio de casos. Diagnóstico y propuesta, $\mathrm{N}^{\circ} 47$, Perú, Consorcio de Investigación Económica y Social y
Programa de Ciencia y Tecnología, pp. 307-447.

Caso Pisco Payet (2010). Álvarez, José CarIos; D'ipolitto, Claudio; Lemos, Einstein, Estudio de caso innovador Pisco Payet.; Innovación empresarial y comportamiento tecnológico sectorial: Experiencias exitosas y estudio de casos. Diagnóstico y propuesta, $N^{\circ} 47$, Perú, Consorcio de Investigación Económica y Social y Programa de Ciencia y Tecnología, pp. 553- 608

\section{Sector Ganadero}

Caso de la Empresa Micaela Bastidas (2010). Martinez, Carla; Rodriguez, Maria; Almeida, Militza. Innovación tecnológica en el desarrollo de familias campesinas dedicadas a la agricultura. Innovación empresarial y comportamiento tecnológico sectorial: Experiencias exitosas y estudio de casos. Diagnóstico y propuesta, $\mathrm{N}^{\circ}$ 47, Perú, Consorcio de Investigación Económica y Social y Programa de Ciencia y Tecnología, pp. 37-100

\section{Sector Maderero}

Caso Guía Metodológica (2008). Gutiérrez, Carmen; Guía Metodológica para transferencia de tecnología en la industria de la madera, Perú, CITE Madera.

\section{Sector Textil}

Caso Exportador Textil y Confecciones (2010). Morón, Eduardo y Serra, César; Tecnología e Innovación: sector exportador textil y confecciones Peruano. Innovación empresarial y comportamiento tecnológico sectorial: Experiencias exitosas y estudio de 
casos. Diagnóstico y propuesta, $\mathrm{N}^{\circ}$ 47, Perú, Consorcio de Investigación Económica y Social y Programa de Ciencia y Tecnología, 185-218

Caso de Innovación en Mejora de Procesos de Producción (2010). Ormachea, Fernando; Quispe, Isabel; Falconi, Rodolfo; La Experiencia de Innovación en mejoras de procesos de producción en el sector textil y confecciones. Innovación empresarial y comportamiento tecnológico sectorial: Experiencias exitosas y estudio de casos. Diagnóstico y propuesta, $\mathrm{N}^{\circ}$ 47, Perú, Consorcio de Investigación Económica y Social y Programa de Ciencia y Tecnología, pp.101-184, (2010).

\section{Sector Salud}

Caso HERSIL (2010). Galléstegui, Manuel; Destefano, Luis; Bernal, Giulliana; Hersil exito en la innovación de productos naturales funcionales para el mercado nacional e internacional. Innovación empresarial y comporta- miento tecnológico sectorial: Experiencias exitosas y estudio de casos. Diagnóstico y propuesta, $\mathrm{N}^{\circ}$ 47, Perú, Consorcio de Investigación Económica y Social y Programa de Ciencia y Tecnología, pp. 479- 551

Caso Instituto Nacional de Salud (2010). Lineamientos de política para la transferencia tecnológica en el Instituto Nacional de Salud, Perú, Instituto Nacional de Salud

\section{Sector Software}

Caso TIC (2010). Rosas, Cecilia y Gonzales, Christian; Acumulación de competencias tecnológicas y comportamiento tecnológica empresarial en el sector de tecnologías de información y comunicación, Innovación empresarial y comportamiento tecnológico sectorial: Experiencias exitosas y estudio de casos. Diagnóstico y propuesta, $N^{\circ} 47$, Perú, Consorcio de Investigación Económica y Social y Programa de Ciencia y Tecnología, pp. 219-306. 